\title{
Guiding Nipple-Areola Complex Reconstruction: Literature Review and Proposal of a New Decision-Making Algorithm
}

\author{
Guido Paolini $^{1}$ - Guido Firmani ${ }^{1}$ (D) Francesca Briganti $^{1} \cdot$ Michail Sorotos $^{2}$ • \\ Fabio Santanelli di Pompeo ${ }^{3}$
}

Received: 6 September 2020/Accepted: 5 November 2020/Published online: 20 November 2020

(C) The Author(s) 2020, corrected publication 2020

\begin{abstract}
Background Nipple-areola complex reconstruction (NAR) most commonly represents the finishing touch to breast reconstruction (BR). Nipple presence is particularly relevant to the patient's psyche, beyond any shadow of doubt. Many reconstructive options have been described in time. Surgery is easy, but final result is often disappointing on the long run.

Methods The goal of this manuscript is to analyze and classify knowledge concerning NAR techniques and the factors that influence success, and then to elaborate a practical evidence-based algorithm. Out of the 3136 available articles as of August 8th, 2020, we selected 172 manuscripts that met inclusion criteria, which we subdivided into 5 main topics of discussion, being the various NAR techniques; patient factors (including patient selection, timing and ideal position); dressings; potential complications and finally, outcomes/patient satisfaction.

Results We found 92 articles describing NAR techniques, 41 addressing patient factors (out of which 17 discussed patient selection, 14 described ideal NAC location, 10 described appropriate timing), 10 comparing dressings, 7
\end{abstract}

Guido Firmani

guido.firmani@uniroma1.it

1 Faculty of Medicine and Psychology, Plastic Surgery Department, Sapienza University of Rome-Sant'Andrea Hospital, Via di Grottarossa, 1035-1039, 00189 Rome, Italy

2 Department of Medicine, Surgery and Dentistry "Scuola Medica Salernitana”, PhD School of Translational Medicine of Development and Active Ageing, Università degli Studi di Salerno, Salerno, Italy

3 Chair of Plastic Surgery, Faculty of Medicine and Psychology, Sapienza University of Rome - Sant'Andrea Hospital, Via di Grottarossa, 1035-1039, 00189 Rome, Italy studying NAR complications, and 22 addressing outcomes and patient satisfaction. We elaborated a comprehensive decision-making algorithm to help narrow down the choice among NAR techniques, and choose the correct strategy according to the various scenarios, and particularly the BR technique and skin envelope.

Conclusions No single NAR technique provides definitive results, which is why we believe there is no "end-all be-all solution". NAR must be approached as a case-by-case situation. Furthermore, despite NAR being such a widely discussed topic in scientific literature, we still found a lack of clinical trials to allow for more thorough recommendations to be elaborated.

Level of Evidence III This journal requires that authors assign a level of evidence to each submission to which Evidence-Based Medicine rankings are applicable. This excludes Review Articles, Book Reviews, and manuscripts that concern Basic Science, Animal Studies, Cadaver Studies, and Experimental Studies. For a full description of these Evidence-Based Medicine ratings, please refer to the Table of Contents or the online Instructions to Authors www.springer.com/00266

Keywords Nipple-areola complex $\cdot$ Nipple-areola reconstruction $\cdot$ Nipple-areola surgery $\cdot$ Breast reconstruction $\cdot$ Breast cancer

\section{Introduction}

Nipple-areola complex reconstruction (NAR) most commonly represents the finishing touch to post-oncologic breast reconstruction (BR) [1-3]. Despite being a minor procedure, it holds major significance to the patients [4], because of its impact on the overall appearance of the 
breast [5-9]. Scientific literature describes an overabundance of possible NAR techniques. Some of those techniques have emerged in time as valid options that are still popular and currently in use, whereas most others have been abandoned throughout the years. No single technique proved to resist loss of nipple projection, which inevitably occurs over time [4]. That is why final results are often disappointing on the long run.

Interestingly enough, BR is offered to cancer patients using a wide variety of options, ranging from implantbased techniques to autologous-based flaps. Different techniques find different indications according to patient and tumor characteristics. Conversely, NAR is approached according to personal preference alone [10], regardless of the circumstances. For this reason, we decided to perform a review of scientific literature to address the most relevant topics regarding NAR to identify what factors can modify the end-result. An "end-all be-all" solution might not exist [11], which is why the goal of this manuscript is to also describe a decision-making algorithm to offer the most satisfying results in NAR in all different varieties of BR patients.

\section{Materials and Methods (Fig. 1)}

We performed a review of scientific literature by searching through the following electronic bibliographic databases: PubMed/MEDLINE, Embase, ScienceDirect, Cochrane Library and Google. We selected all eligible articles written in English and French, and pertaining to human-based topics, by identifying pertinent index terms (Medical Subject Heading [MeSH] ) and relevant free-text keywords. The search terms we used were "Nipple-areola complex" OR "Nipple" OR "Breast cancer" AND "Surgery" OR "Reconstruction" OR "Plastic Surgery". We classified the articles based on five main topics of discussion, being NAR techniques; patient factors, including ideal patient selection, timing and position of the NAC; dressings and protective devices; potential complications; and finally, outcomes/patient satisfaction. Ideal NAR patient selection specifically included Stage I-III breast cancer patients that underwent skin-sparing, skin-reducing or radical mastectomy. Metastatic breast cancer (Stage IV) and breast cancer treated with local treatments, including breast-conserving surgery and nipple-sparing mastectomy, were excluded. Our aim was to identify evidence-based measures to offer optimal NAR results to breast cancer patients, and to elaborate a decision-making algorithm to guide the choice of the techniques. The review search was conducted between February 2020 and August 2020 by G.F. and F.B. Four reviewers (G.P. G.F., F.B., and M.S.) independently reviewed the titles and abstracts yielded by this comprehensive search and subsequently selected articles based on the predetermined inclusion and exclusion criteria. Disagreements were resolved by an additional reviewer (F.S.d.P.) or through consensus-based discussion. Out of the 3136 articles that were available as of August 8th, 2020, we excluded all duplicate articles and articles discussing nipple-sparing mastectomy, BR, nipple inversion, nipple hypertrophy or other benign NAC conditions, selecting a total of 172 articles.

\section{Results}

We found 92 articles describing NAR techniques, 41 addressing patient factors (out of which 17 discussed patient selection, 14 described ideal NAC location, 10 described appropriate timing), 10 comparing dressings, 7 studying NAR complications, and 22 addressing outcomes and patient satisfaction.

\section{Nipple and Areola Reconstruction Techniques}

We found 92 articles that discussed nipple and/or areola reconstruction techniques following mastectomy. There are over 60 counts of unique NAR techniques that have been described in the past 8 decades, the first dating all the way back to 1944 with Adams' NAC transplantation during a breast reduction procedure [12], and to 1946 with Berson's attempt at recreating a nipple prominence with a local flap for a breast cancer patient [13]. Although complete description of all existing NAR techniques is beyond the scope of this manuscript, we will provide an accurate account of all existing categories described in the literature.

Available techniques for areola reconstruction include skin grafting, banking and replantation, and tattooing. Skin grafting is an adjunct technique to other NAR procedures that recreate the nipple. It originally started in 1949 with Adams et al. [14], and was later modified by Brent et al. in 1977 [15]. It consists in harvesting a circular-shaped fullthickness skin graft and placing it around the neo-nipple. Donor site is usually selected according to the original color of the areola: if light pink, the graft can be harvested from the oral mucosa. If darker, suitable donor sites include the labia minora and majora from the groin $[16,17]$, the buttock [18] or the upper thigh [19], because skin harvested from these areas supposedly tends to hyperpigment [6]. Some propose harvesting the outer rim of the contralateral areola, which can be useful in patients with large NAC who would simultaneously benefit from an areolar reduction [20]. If no donor site is available, Seaman proposes using an acellular dermal matrix (Alloderm) as an onlay graft [21]. NAC banking, first introduced by Millard in 1971 [22], consists in removing NAC from the breast and 
Fig. 1 Flow diagram representation of the search strategy with included and excluded articles

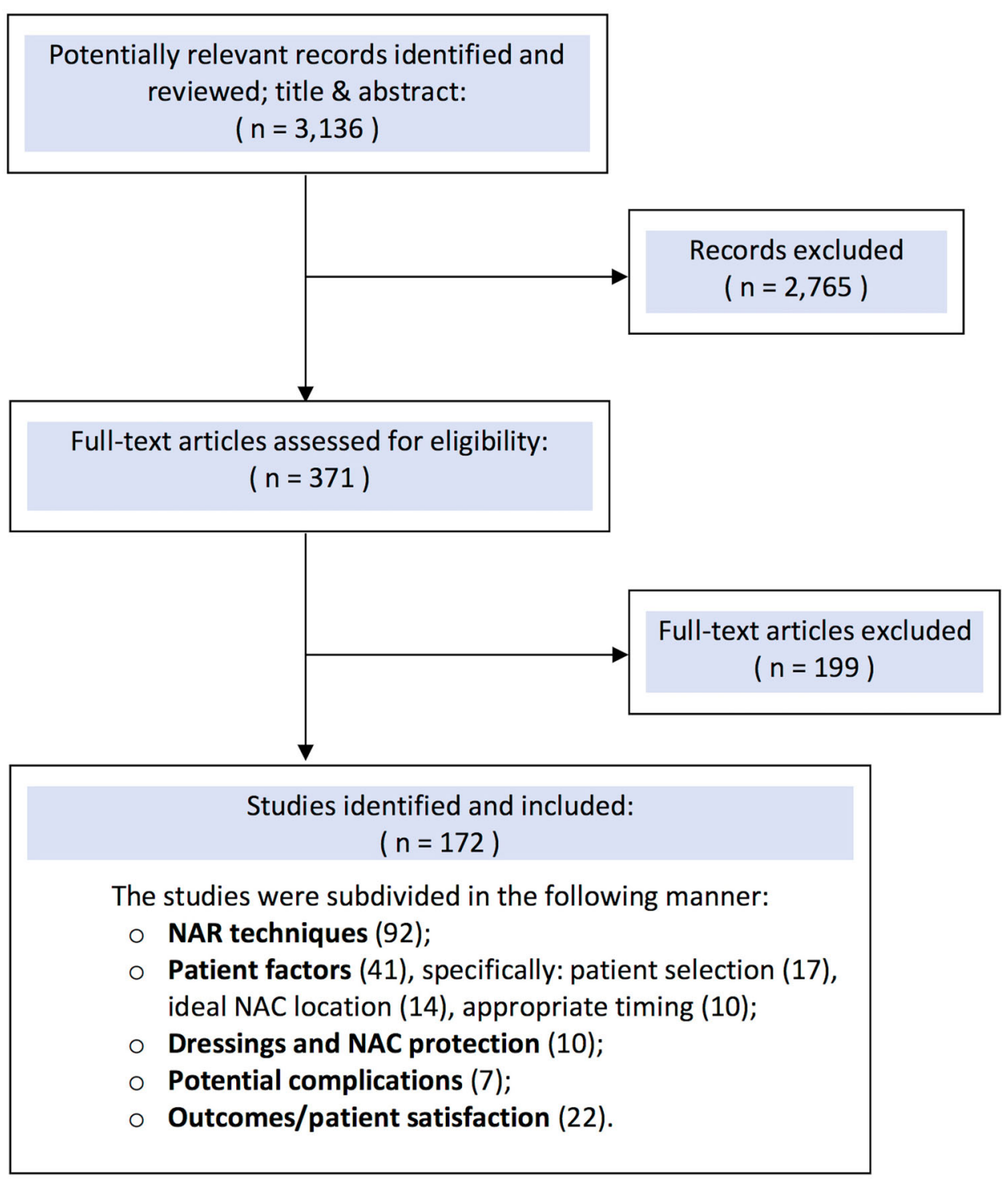

replanting them in the groin area to allow time for the BR to heal. After extemporaneous/definitive examination, the spared NAC is reattached on the reconstructed breast to complete NAR (Fig 2). Some authors describe cryopreservation techniques for replantation after definitive histologic exam report [23, 24]. With the latter approach, replantation occurs after 5.8 months on average. If cancer cells are diagnosed in the meantime, during histological examination, the specimens are discarded. Intradermal tattooing (or dermopigmentation) for areolar reconstruction was first introduced by Bunchman et al. in 1974 [25] and popularized by Becker in 1986 [26]. It usually lasts 20 to 30 minutes per NAC in an outpatient setting. It might require topically applied anesthetic according to the patient's degree of sensation [11]. The operator can offer a wide variety of choices in terms of pigment selection according to the contralateral areola's color in unilateral
NAR [11], or to the patient's skin tone in bilateral NAR. Nevertheless, dermopigmentation is just an adjunct to other techniques, as it only provides the illusion of a texture without a projection.

Available techniques for nipple reconstruction: nipple sharing, local flaps, augmentation grafting using autologous or heterologous materials, prosthesis or 3D tattoos. Millard et al. first introduced nipple sharing in 1972 [27]. Its use remains popular when contralateral nipple has a projection of over $1 \mathrm{~cm}$ [28]. There are two main techniques: longitudinal splitting and decapitation [29]. For the latter approach, at least $50 \%$ of the donor nipple's original height must be left intact to ensure adequate residual projection and sensation. The composite nipple is sutured on a de-epithelialized recipient area using interrupted sutures. Most authors advocate for the use of stitches to close the tip of the donor nipple [29], though Haslik et al. favor second 


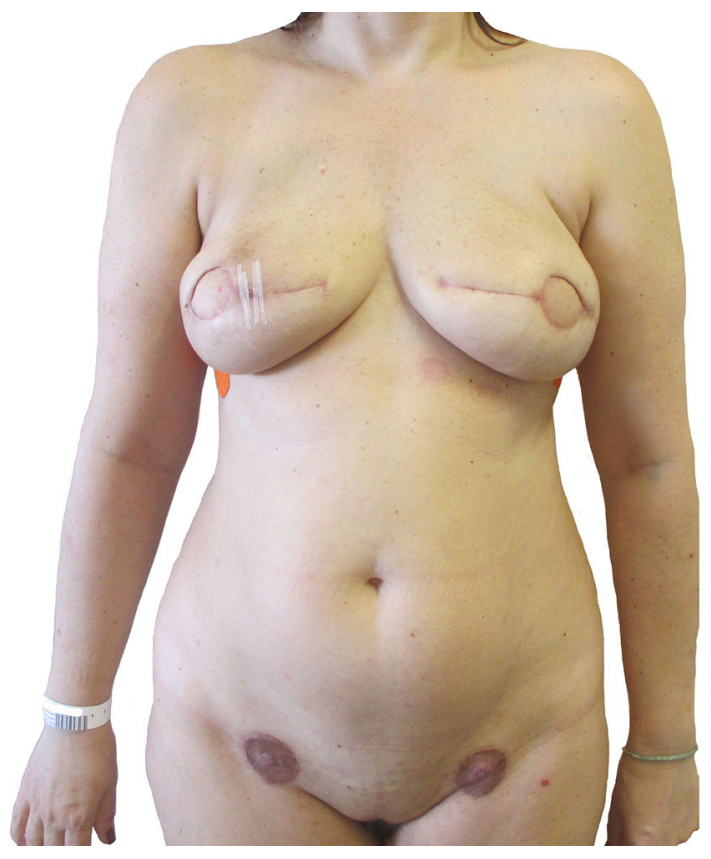

Fig. 2 Patient at 3 weeks follow-up after bilateral skin-sparing mastectomy and immediate breast reconstruction with fat-augmented latissimus dorsi (FALD) flap for bilateral infiltrating ductal carcinoma $(L e f t)$. Areolas were initially replaced with LD skin and NAC were banked in the inguinal crease. Right NAC was later discarded for oncologic reasons, and the new NAC was reconstructed with C-V flap

intention healing, which occurs in 10 days on average and provides an equally acceptable scar and sensibility [30]. Local flaps represent the most commonly described technique for nipple reconstruction [6,31]. They have significantly evolved in time, and to date, over 60 techniques have been described. They can generally be classified into three categories according to the principle upon which they are raised [5]: centrally based flaps, subdermal pedicled flaps and pull-out/purse-string flaps. Centrally based flaps include Berson's “pseudo-nipple" reconstruction, introduced in 1946 which consisted in using 3 triangular splitthickness skin flaps, Barton's blunted Maltese cross in 1982, Little's quadrapod flap in 1983, and Cohen's pinwheel flap in 1986. Subdermal pedicle flaps represent the most common category of local flaps. They can be based on a single pedicle, including Snyder's V-Y advancement flap in 1972, Little's skate flap in 1987, Anton and Hartrampf's star flap in 1991, Jones and Bostwick's C-V flap in 1994, and Guerra's arrow flap in 2003; they can be bipedicled, such as Kroll's double-opposing-tab flap in 1989, Cronin's S-flap in 1988 and Lossing's modified S-flap in 1998 (Fig 3); or they can even be based on a triple pedicle such as Krogsgaard's triple flap design in 2019 [32]. Pull-out/purse-string flaps include Hallock's H flap in 1993, Eng's Bell flap in 1996, Hamori's Top-hat Flap in 1998, Shestak's double opposing peri-areolar flap in 2007

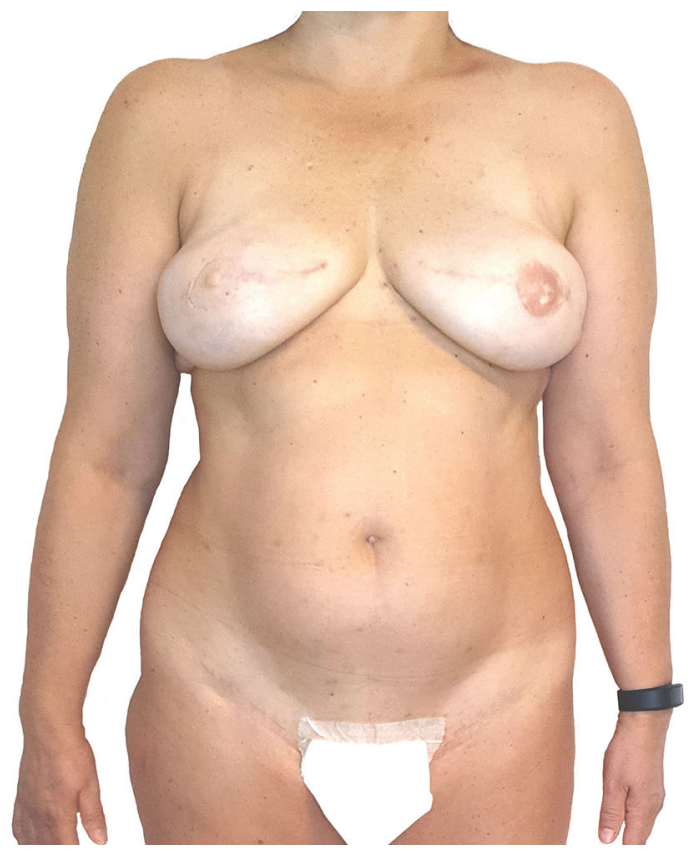

3 months later. Left NAC was transplanted 3 months later from the inguinal region to the breast mound, showing mild discoloration and loss of nipple projection. Patient refused any additional procedures to reconstruct the right areola and improve the left and returned to follow-up 2 years later (Right)

and the Hammond Flap in 2007. Most local flaps are considered "dermal-fat" flaps because they consist in raising full-thickness skin flaps that reach subcutaneous tissues. However, some authors have described strictly dermal flaps that can be safely used in implant-based BR patients, even with a history of radiotherapy (RT), such as Rem et al.'s inferiorly pedicled dermal flap [33]. Augmentation grafting can be approached as a primary NAR. However, it generally represents a secondary/revision measure to improve structural support and enhance the projection of a flattened neo-nipple [11]. It requires the use of either autologous or heterologous materials [7]. Autologous tissues include dermis [34, 35], adipose tissue [36], cartilage (from the ribs or the outer ear) and mucosa (from the gums of the oral cavity or the rima ani at the coccygeal level) [1]. Costal rib cartilage can be harvested during free flap-based BR procedures, when internal mammary vessels are selected as recipient site $[37,38]$. In these cases, internal mammary vessel dissection requires the resection of a small portion of costal cartilage which can be banked and reused for augmentation grafting of the reconstructed nipple. Used heterologous materials can be classified as synthetic or allogenic [7]. Synthetic materials are foreign bodies which serve as internal implants and include silicone gel or rods [39], hyaluronic acid, calcium hydroxylapatite (Radiesse $\left.^{\mathrm{TM}}\right)$ [40], artificial bone substance 


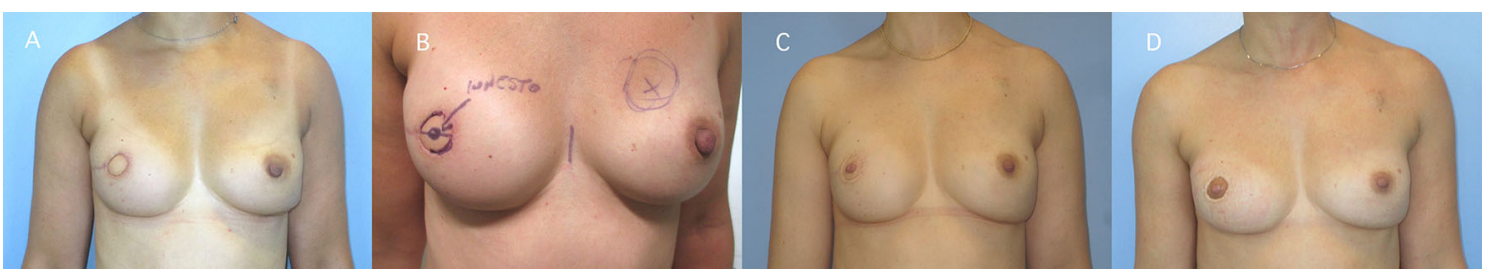

Fig. 3 Patient at 12-month follow-up for left nipple-sparing mastectomy and right skin-sparing mastectomy, with immediate breast reconstruction using a bilateral DIEP flap (a). She underwent right nipple reconstruction using Lossing's S-flap and a fat grafting session

$\left(\right.$ Ceratite $\left.^{\mathrm{TM}}\right)$ [41, 42] and polytetrafluoroethylene [43]. Acellular dermal matrices (AlloDerm ${ }^{\mathrm{TM}}$, GCDerm, SureDerm) and the Biologic Collagen Cylinder [10] are classified as allogenic materials [11, 44]. They use decellularized nipple scaffolds that support recellularization with the host's own cells [45, 46]. When patients refuse additional surgeries or cannot safely undergo them, they may be eligible for 3D tattooing, which unlike traditional dermopigmentation, includes shadings and details, creating an optical illusion to compensate for the lack of a nipple $[9,47,48]$. Another solution is external prosthetics, which represent an inexpensive and completely atraumatic solution ${ }^{8}$ but not a reconstructive option.

\section{Patient Factors}

We found 41 articles discussing patient factors related to NAR. Out of those, 17 articles discussed patient selection for a successful NAR approach. The ideal candidate to NAR procedures has aesthetically pleasant breast mounds with adequately vascularized soft tissues [3]. Certain risk factors can negatively impact wound healing and make NAR more difficult to achieve, including smoking and RT $[49,50]$, that increase risk for necrosis of the neo-nipple $[6,50,51]$. The chosen BR technique is also relevant when planning NAR. Breast-implant reconstruction patients usually have thin, contracted and poorly vascularized soft tissues that are more at risk of reconstructive failures. Irradiated patients with breast implants have a breast skin envelope that is thinned even further. Raising dermal or subcutaneous skin flaps for NAR in these cases may be contraindicated $[3,26]$, and nipple sharing is considered the safest technique [29, 37, 52, 53]. However, Yong Hong et al. routinely perform NAR on implant-based breast mounds using local flaps by carefully selecting patients [54]. They only perform the procedure when: (a) tissue expansion exceeds the mastectomy weight; (b) the expanded skin is sufficiently elastic, and (c) sufficiently thick. Nevertheless, Chao [55] described a "delay procedure" to safely implement local flaps, even in irradiated patients with breast implants. It consists of three steps: (1) the of the left breast during the same setting under general anesthesia 6 months later (b). Patient returned 4 months later for a single dermopigmentation session for areolar reconstruction (c) and 5 more months later for follow-up (d)

incision of the skin and dermis following the shape of the flap; (2) a delay of 2.5 weeks on average, to ensure viability of the skin flaps, then the raising of the flaps; (3) and finally areola tattooing several months later. Bernard advocates for autologous fat grafting sessions along the markings of a chosen flap design, to increase subdermal fat thickness. He then delays the procedure to stabilize the result and then raises the flap to complete NAR [33]. In patients with previous scarring or who previously underwent NAR and require revision, Riccio et al. advise using the V-Y flap or Kroll's double-opposing flap to incorporate mastectomy scars, thereby decreasing new scar formation and improving aesthetic results. Other local flaps that incorporate scars include Cronin and Lossing's S-flap [56].

We found 14 articles that studied the ideal position for successful neo-nipple placement in NAR planning. Authors describe NAR placement according to the position on the breast mound, along with shape, size and projection of the nipple [2, 3]. In unilateral reconstructions, the contralateral nipple serves as a template. In bilateral reconstructions, there is no general rule and the surgeon must select the most suitable and aesthetically pleasant position of the neonipple using anatomical landmarks [45], all the while keeping in mind the preference of the patient [1]. Lewin et al. suggested that the ideal NAC is located in the middle of the breast, vertically and slightly lateral to the midpoint horizontally [57], while Laschuk et al. proposed the "rule of thirds", according to which the areola should represent just under one third of the base width, and the nipple should represent about one third of the areolar diameter [58]. Nevertheless, surgeons will usually place the NAC on the point of highest projection on the breast mound [30], which often corresponds to a sternal notch-to-nipple distance of $19-21 \mathrm{~cm}$ and a nipple-to-inframammary fold distance of 7-8 cm [59]. In implant-based BR, Young Hong advises adding $0.5 \mathrm{~cm}$ to the sternal notch-to-nipple distance when replacing a tissue expander with a definitive implant, since capsular contracture is a common occurrence that should be taken into account [55]. He discusses adding $1.0 \mathrm{~cm}$ instead when planning to perform contralateral balancing procedures (mastopexy, breast 
reduction), to compensate for the downward shift of the contralateral nipple that will occur over time. In regard to ideal NAC measurements, some authors recommend a 4-7 $\mathrm{mm}$ nipple diameter, a height of $>1 \mathrm{~cm}$ and an areolar diameter of $4.2-4.5 \mathrm{~cm}^{4}$. A review of 600 reconstructed NAC reported an average diameter of $1.3 \mathrm{~cm}$, a height of $0.9 \mathrm{~cm}$ and a 1:3 nipple-to-areola ratio [60, 61]. Furthermore, when NAR is planned using local flaps, preoperative markings usually incorporate an overcorrection by $25-50 \%$ of the desired result $[62,63]$, since flattening is inevitable [3, 64].

We found 10 articles that discussed the most appropriate timing when planning for NAR. There are reports in the literature of surgeons performing NAR immediately (at the time of BR) $[55,65,66]$. However, there is a general agreement in favoring delayed nipple reconstruction, as a final step at least 3-6 months after BR surgery [3], and 2-4 months after large revisions [11, 67], once the breast mound is stable, to avoid a potentially asymmetric nipple placement if placed too early [5]. Surgeons should also wait for their patients to conclude their adjuvant chemotherapy/RT regimens before planning NAR. In fact, irradiating a newly reconstructed NAC increases the risk of poor wound healing and flattening. Furthermore, if patient has undergone implant-based BR, RT increases the risk of capsular contraction which might dislocate the reconstructed nipple causing malposition [3]. In regard to areolar reconstruction, dermopigmentation is delayed by at least 6 to 12 weeks from the nipple reconstruction, to allow proper healing [1]. Some authors choose to reconstruct the nipple with flaps immediately after having tattooed the surrounding skin [68], stating that this approach supposedly guarantees an even uptake of pigment, even along the scars. However, most authors do not recommend this approach, since the additional trauma of flap dissection to the pigmented skin might reduce vascularity of the flap [1].

\section{Dressings and Nac Protection}

We found 10 articles addressing reconstructed nipple protection and dressings. The main concern in the postoperative course consists in protecting the nipple, and ensuring a correct compression over the skin graft (if the latter approach was used to reconstruct the areola) while still avoiding direct pressure to the reconstructed nipple for the first 7 days [69]. Many authors describe various types of dressings. In 1995, Monteiro advised anchoring the graft with eight symmetrically placed 4-0 silk stitches, then placing a petrolatum gauze with a central cut over the nipple, covering the entire graft [70]. He then proposed placing the rubber stopper of a $60-\mathrm{mL}$ syringe over the nipple, with cotton balls packed around it, then folding the petrolatum gauze over the stopper and the dressing, and tying the sutures. In 1997, Papay et al. proposed a similar technique but using the non-adherent xeroform gauze on the skin graft and four-to-five layers of DuoDerm, both with a central hole for the nipple projection [71]. Liew et al. described in 2001 a technique using a Tielle hydropolymer dressing with a central hole to accommodate the nipple and then placing an extra layer of gauze and microfoam tape as padding [72]. Saravolac et al. described the use of a moldable thermoplastic thick foam with a hole in the middle as a nipple shield [73]. Lim et al. found in 2010 that Gamgee tissue pads could be used as a dressing to improve the perfusion of the reconstructed nipple [74], while Salgarello in 2008 [75] and Weissman in 2010 [76] investigated the use of silicone shields as a way to better protect nipple from compression. Sircar [77] and Staruch [78] recommended placing a Cartella eye-shield or similar eye protectors, over the NAR dressings, while Rosing et al. tested in 2010 the use of the Asteame Nipple Guard [79]. In general, excessive compression of the nipple should be avoided to prevent microcirculation impairment [75].

\section{Complications to Nar}

We found 7 articles discussing NAR complications. There are no significant differences in terms of complication rates between the various local flap techniques [6]. The most commonly reported complications include partial and total nipple necrosis $(1-29 \%)$, which was found to be more prominent in irradiated patients [11], infection (0.9-16\%) and complete loss of projection which warranted a reoperation $(2-24 \%)$. The most severe reported complication was the loss of breast implants due to their exposure [80]. Other complications include donor-site morbidity. Nipple sharing technique can cause major concerns in terms of loss of sensibility in the healthy nipple [81]. Autologous augmentation grafting can cause donor site morbidity (i.e., ribs or outer ear for cartilage, gums of the oral cavity or the rima ani for mucosa) [1]. A meta-analysis revealed that augmentation grafting with synthetic materials has a higher rate of complications [63], especially Ceratite [42]. On the other hand, allogenic materials provide a projection comparable to that of autologous tissues [7], with no donor-site morbidity and lower overall complication rate than that of both autologous and synthetic grafts [45, 82]. However, they represent the most expensive alternative out of the three [45]. Dermopigmentation gained popularity for being the least invasive areolar reconstruction technique, and for not carrying significant donor-site morbidity. It has a low risk of complications, which mainly consist in local infections, wound dehiscence if performed too soon after local flaps [83], and rare allergic and photosensitive reactions caused by pigments [1]. 


\section{Patient Satisfaction and Outcomes}

Patients who undergo NAR are overall more satisfied with their BR than those who do not $[3,84]$. However, patient satisfaction related to NAR results mostly depends on the maintenance of nipple projection and color matching [29, 85, 86]. Conversely, NAR dissatisfaction usually stems from a lack of long-term nipple projection and color mismatch, as well as unappealing shape and nipple malposition [3, 85]. We found 22 articles discussing NAR satisfaction and outcomes. Jabor et al. found that the longer the interval between breast mound reconstruction and NAR, the less satisfied the patient [85]. Surprisingly, they found that breast mound type, RT and NAR technique had no influence on patient satisfaction [85]. The most common outcome to NAR is loss of projection, caused by the flattening that often occurs over time [4], regardless of which technique was used for the breast mound (autologous vs implant-based) [11, 68]. This is due to retraction forces of the surrounding and underlying tissues and scar contraction which reduces blood flow [5]. However, it is more evident after tissue expansion (where the dermis and subcutaneous tissues are thinned) and following adjuvant RT [45]. Nevertheless, it is less pronounced on implant-only breast mounds [87], probably because the implant provides a more solid foundation. For autologous BR, abdominally based flaps and gracilis flaps provide a relatively thin dermis, which makes them more prone to tissue contraction and nipple projection loss $[8,35,45,88]$ in comparison with latissimus dorsi and gluteal flaps, which provide a thicker dermis [45]. Local flaps lose projection with a range from $17 \%$ to over $75 \%$ [11, 81], and an average of $25-50 \%$ [1]. Current trends in local flaps reject centrally based patterns because they fail at creating long-lasting projections. They are characterized by centrifugal retraction forces which cause increased tissue contraction, leading to shrinkage of the flap [45]. NAR has moved toward local flaps with simple designs and subdermal pedicles [5]. The more complicated the local flap design, the more the scarring, which reduces blood supply to the skin flaps and increases tissue contraction thus causing shrinkage and loss of projection [5]. Subdermal pedicle flaps exert considerably lower retraction forces and redistribute them more evenly, which translates into a longerlasting projection. In regard to areola reconstruction, achieving the correct color match constitutes the main challenge [5]. Areolar grafting has lost popularity because of patient dissatisfaction with pigmentation, which is hard to predict, and has higher donor site morbidity [1]. NAC banking and replantation has also been abandoned or limited for safety concerns, as several cases of cancer cell infiltration in inguinal lymph nodes have been reported $[89,90]$. Furthermore, banking frequently damages the
NAC causing loss of projection and pigmentation, especially when using cryopreservation [23]. The authors that still advocate its use suggest applying it only when breast cancers are remote from the native NAC [3]. Dermopigmentation's main drawback is fading [11], which occurs over time in as many as $60 \%$ of patients $[5,11,69]$. However, this is manageable with touch-up sessions to apply new pigment [11]. Additionally, areolar tattooing requires a learning curve to apply the pigment at the correct depth, being the upper and mid-papillary dermis [5]. If too superficial, the pigment lies in the epidermis that sheds at 30-days turnover. If too deep, lymphatic vessels drain the pigment. In both cases, the tattoo fades causing a dissatisfying result $[1,5]$. This is why some authors advise for the use of a professional tattoo artist, which can, however, be costly.

\section{The Sant'Andrea University Hospital (SAUH) Decision-Making Algorithm for NAR (Fig. 4 a, b)}

This practical algorithm has been elaborated following an accurate review of 172 manuscripts discussing various aspects of NAR. It describes 6 categories of possible NAR approaches: 1) nipple sharing, 2) NAC banking/replantation, 3) "dermal-fat" flaps, 4) strictly dermal flaps, 5) tattooing and 6) no reconstruction at all. The starting point should take into consideration laterality. When nipple reconstruction is unilateral, the contralateral side should be used as template. When the unaffected nipple has a projection $>1 \mathrm{~cm}$, consider using nipple sharing, otherwise use local flaps. The most commonly used flaps include the skate, star, C-V and arrow flaps [44]. Conversely, when reconstruction is bilateral, previously mentioned anatomical landmarks should be applied to appropriately locate the NAC. Mastectomy type and BR technique can influence end-results of NAR and therefore assess the quality of the skin envelope before choosing an option. As plastic surgeons, we designed the algorithm putting an emphasis on the used BR technique, separating implant and autologousbased procedures, and later characteristics of the skin envelope. In patients that underwent staged expander/implant reconstruction, dermis and subcutaneous tissues may be thinned. In these cases, nipple sharing might represent a safe option. If said option is not possible and usual flaps do not guarantee an uneventful outcome, Chao et al.'s delayed 3 -step technique for local flaps is feasible. Alternatively, 3D tattooing can provide satisfactory results. In Direct-ToImplant BR, quality of dermis and subcutaneous tissues depends on patient characteristics and aggressiveness of the skin-sparing mastectomy (SSM). In cases of SSM with an average skin thickness, local flaps may be attempted, but dermal pedicle-based techniques should be favored to reduce the risk of implant exposure [33]. In the case of 

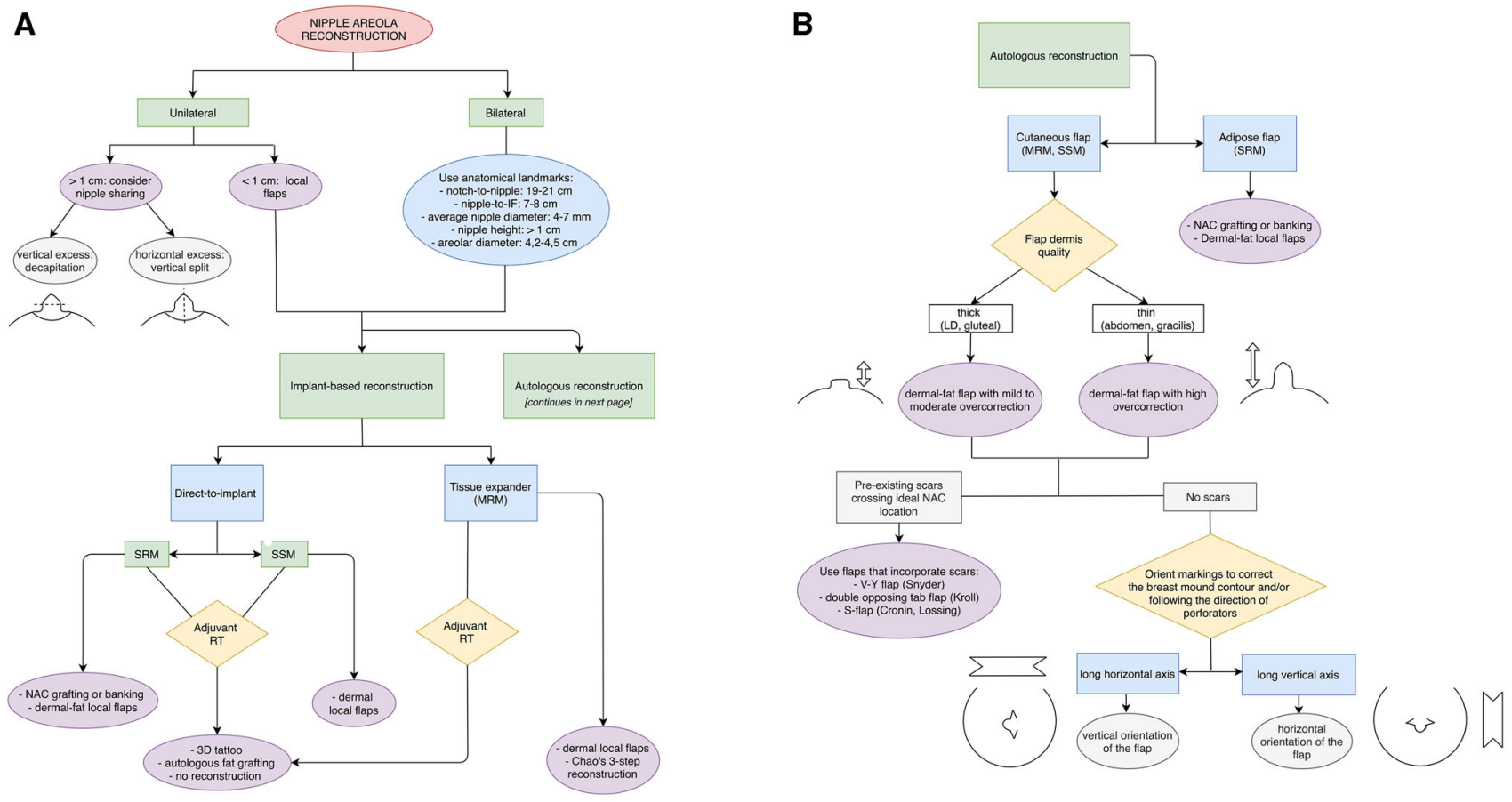

Fig. 4 The Sant'Andrea University Hospital (SAUH) decision-making algorithm for nipple-areola reconstruction, with (a) general recommendations and specific recommendations for implant-based BR, and (b) specific recommendations for autologous-based BR
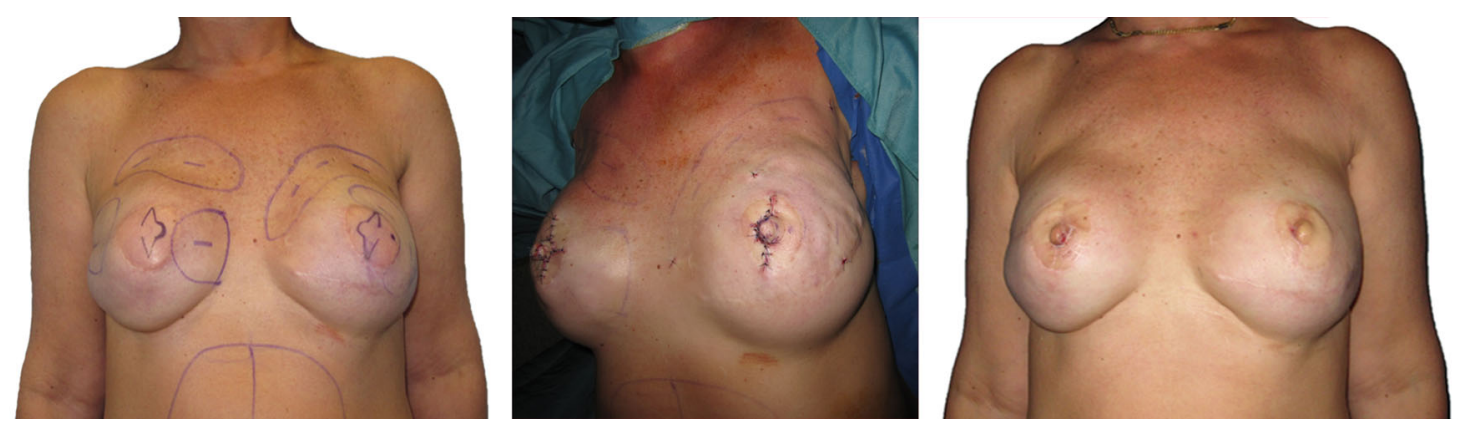

Fig. 5 Patient at 6-month follow-up after secondary breast reconstruction with implant-enhanced latissimus dorsi flap (Left) after failed implant reconstruction of bilateral skin-sparing mastectomy. Patient underwent a fat grafting session and bilateral C-V flap for nipple reconstruction during the same operative setting (Center). Preoperative markings were oriented in accordance with the NAR algorithm to reduce breast mound asymmetries. Patient at 6-month follow-up following NAR (Right) skin-reducing mastectomies (SRM) in which NAC can be spared, NAC banking and immediate [91] delayed replantation may be used when oncological concerns are ruled out. In the case of adjuvant RT, skin might become fibrotic and thin. In these cases, autologous fat grafting can be used before planning local flaps [33]; otherwise, NAR should be avoided, opting for a 3D tattoo instead. In autologous-based BR, in patients undergoing SRM with NAC preservation, NAC may be immediately reimplanted over the de-epithelialized dermis of the underlying buried autologous flap, to avoid the risks of delayed healing of the mastectomy skin flaps due to poor terminal vascularization.
NAC can otherwise be banked, performing replantation at a later stage, once flap has settled in the correct position (Fig 2). In patients that underwent SSM or radical mastectomy, NAC is preferably reconstructed directly onto autologous flap skin due to improved vascularity. In these cases, the quality of the flap dermis can affect NAR. Latissimus dorsi and gluteal flaps provide a thick dermis, making local flaps less pliable but requiring only mild-to-moderate overcorrection when planning NAR. On the other hand, abdominal and gracilis flaps provide a thinner dermis which make them more pliable and easily moldable but require a higher degree of overcorrection. In either case, if a pre-existing 
scar is located on the ideal position for the NAC, it would be most suitable to select a local flap technique that incorporates the scar, such as Snyder's V-Y flap, Kroll's double-opposing tab flap or Cronin's S-flap. If no scars are present, local flap markings can be oriented in a specific manner to correct breast mound contour asymmetries. If the transverse diameter is too long, markings may be oriented vertically to shorten the mound length. If the vertical axis is excessive, markings may be oriented horizontally to reduce mound width [35] (Fig 5). Another element worth taking into consideration in autologous-based BR is to orient local flap markings away from scars to take advantage of the flap's vascular autonomization, or along the direction of the perforators, in the vicinity of the perforasome "hot spot", where blood supply is increased [92] and thus might reduce the risk of projection loss.

\section{Discussion}

Ingenious surgical innovations have led to the creation of an impressive number of NAR techniques that all aim at providing natural-looking projections with adequate shape and size. Most described techniques have been relegated to the past [1, 64]. However, some have grown to become widely accepted and are still popular today. Nevertheless, all of the currently available options still fail at providing consistent results [7, 93], when indifferently used with different reconstructive modalities. This problem may be related to the fact that previous authors failed at pointing out the real variables affecting NAR success, mainly addressing the efficacy of their preferred reconstructing technique more than the substratum on which it was realized (reconstructive technique and consequent skin envelope).

We found just two algorithms in the literature that described recommendations on how to approach NAR. Lee et al. introduced the Kyungpook National University Hospital (KNUH) algorithm in 2019 [94]. It is based on the experience that the authors developed following a study on 21 patients who underwent implant-based BR and NAR using $\mathrm{C}-\mathrm{V}$ or Hammond flap and that were followed-up for 12 months to assess results. This algorithm provides recommendations on when to perform NAR immediately and when to delay them, and clarifies how to manage potential complications. However, it is limited by three elements: firstly the small number of patients recruited in the study, secondly the lack of diversity in NAR techniques, since only 2 local flaps were tested, disregarding other safer alternatives in implant-based BR such as nipple sharing [29], and thirdly they recruited only implant-based reconstructions, ignoring autologous ones. Jian et al. described a NAC reconstruction algorithm in 2018 that was based on scientific literature. It addresses NAR in both implant and autologous-based BR [95]. The main limitation to their algorithm is the indeterminateness of the recommendations which we found when addressing NAR in autologous BR. The authors select NAR techniques according to laterality and contralateral nipple size alone. We believe that the type of breast mound reconstruction and consequent skin envelope calls for different nipple reconstructive techniques and affects the success of the chosen one. We found that several factors can impact the choice of the techniques and their success: the type of skin envelope, the type of autologous flap used (since it can affect the thickness of the dermis and therefore the need for overcorrecting local flap markings), the presence of scarring across NAC location and the direction of perforators (to maximize local flap vascularity) and finally the presence of breast contour asymmetries (to plan local flap markings accordingly, in order to correct them). Therefore, all mentioned factors must be taken into consideration.

Despite being technically simple, NAR are still surgical procedures that are not exempt from possible complications that can tarnish the end-result. Nipple reconstruction is considered a failure when $>80 \%$ of the starting projection is lost in time [64]. In these cases, revision procedures are available for secondary NAR reconstruction. Some authors advocate the use of augmentation grafting to enhance the projection [33], while others repeat local flaps [96]. However, added scarring reduces blood flow and increases the risk of projection $\operatorname{loss}^{5}$. In those cases, we recommend the use of flaps that incorporate previous scars [57].

Additionally, we found very few accounts of randomized or controlled clinical trials attempting to compare specific NAR techniques between each other [4]. Shestak et al. demonstrated the superiority of the skate and the star flap to the bell flap [64]. Rubino et al. proved that the arrow flap was superior to a modification of the star flap [97], and Alfano et al. proved that the skate flap retained nipple projection for longer than the star flap [98]. Kroll compared the double-opposing tab flap to the star flap, finding the first to retain a slightly better nipple projection after 2 years of follow-up (2.42 vs $1.97 \mathrm{~mm}$ ), particularly over breast mounds reconstructed with Transverse Rectus Abdominis Muscle (TRAM) flaps [99]. Pizzonia et al. compared their purse-string and immediate fat grafting augmentation technique with traditional techniques in patients with thin breast skin envelope, obtaining worse projection (5 $\pm 2 \mathrm{~mm}$ vs $8 \pm 2 \mathrm{~mm}$ ) but lower projection loss [100].

NAR is widely performed and represents a pivotal factor in patient satisfaction after BR [4]. So much so that scientific literature brims with research papers on the subject. And yet, examples of clinical trials available are few and far between. This hinders the possibility of presenting more 
specific recommendations that are based on solid and undeniable scientific evidence. Trials evaluating the efficacy and results of a single technique in different clinical settings or different techniques in a single clinical scenario are welcome.

\section{Conclusion}

We are still currently far from the ideal NAC reconstruction method, and with there still not being an "end-all beall" solution, we recommend choosing an option on a caseby-case situation, using our proposed decision-making algorithm to narrow down the available options. We also found a dire need for more evidence-based research on the subject of NAR to make our recommendations more thorough in the future.

Funding Open access funding provided by Università degli Studi di Roma La Sapienza within the CRUI-CARE Agreement.. Open access funding provided by Università degli Studi di Roma La Sapienza within the CRUI-CARE Agreement. The authors received no financial support for the research, authorship, and/or publication of this article.

\section{Compliance with Ethical Standards}

Conflict of interest The authors declare that they have no conflicts of interest.

Human and Animal Rights This article does not contain any studies with human participants or animals performed by any of the authors.

Open Access This article is licensed under a Creative Commons Attribution 4.0 International License, which permits use, sharing, adaptation, distribution and reproduction in any medium or format, as long as you give appropriate credit to the original author(s) and the source, provide a link to the Creative Commons licence, and indicate if changes were made. The images or other third party material in this article are included in the article's Creative Commons licence, unless indicated otherwise in a credit line to the material. If material is not included in the article's Creative Commons licence and your intended use is not permitted by statutory regulation or exceeds the permitted use, you will need to obtain permission directly from the copyright holder. To view a copy of this licence, visit http://creativecommons. org/licenses/by/4.0/.

\section{References}

1. Farhadi J, Maksvytyte GK, Schaefer DJ, Pierer G, Scheufler O (2006) Reconstruction of the nipple-areola complex: an update. J Plast Reconstr Aesthet Surg 59(1):40-53. https://doi.org/10. 1016/j.bjps.2005.08.006

2. Boccola MA, Savage J, Rozen WM, Ashton MW, Milner C, Rahdon R, Whitaker IS (2010) Surgical correction and reconstruction of the nipple-areola complex: current review of techniques. J Reconstr Microsurg 26(9):589-600. https://doi.org/10. 1055/s-0030-1263290
3. Vendemia N, Mesbahi AN, McCarthy CM, Disa JJ (2008) Nipple areola reconstruction. Cancer J 14(4):253-257. https:// doi.org/10.1097/PPO.0b013e31817fbe72

4. Momeni A, Becker A, Torio-Padron N, Iblher N, Stark GB, Bannasch H (2008) Nipple reconstruction: evidence-based trials in the plastic surgical literature. Aesthet Plast Surg 32(1):18-20. https://doi.org/10.1007/s00266-007-9039-0

5. Nimboriboonporn A, Chuthapisith S (2014) Nipple-areola complex reconstruction. Gland Surg 3(1):35-42. https://doi.org/ 10.3978/j.issn.2227-684X.2014.02.06

6. Sisti A, Grimaldi L, Tassinari J et al (2016) Nipple-areola complex reconstruction techniques: a literature review. Eur J Surg Oncol 42(4):441-465. https://doi.org/10.1016/j.ejso.2016. 01.003

7. Winocour S, Saksena A, Oh C et al (2016) A systematic review of comparison of autologous, allogeneic, and synthetic augmentation grafts in nipple reconstruction. Plast Reconstr Surg 137(1):14e-23e. 0000000000001861

8. Satteson ES, Brown BJ, Nahabedian MY (2017) Nipple-areolar complex reconstruction and patient satisfaction: a systematic review and metaanalysis. Gland Surg 6(1):4-13. https://doi.org/ 10.21037/gs.2016.08.01

9. Sisti A, Tassinari J, Cuomo R, Brandi C, Nisi G, Grimaldi L et al (2017) Nipple-areola complex reconstruction. NippleAreolar Complex Reconst. https://doi.org/10.1007/978-3-31960925-6_43

10. Tierney BP, Hodde JP, Changkuon DI (2014) Biologic collagen cylinder with skate flap technique for nipple reconstruction. Plast Surg Int 2014:194087. https://doi.org/10.1155/2014/ 194087

11. Nahabedian Maurice Y (2007) Nipple reconstruction. Clin Plast Surg 34(1):131-137. https://doi.org/10.1016/j.cps.2006.11.009

12. Adams WM (1944) Free transplantation of the nipples and areolae in breast hypertrophy. Surgery 15:186-195

13. Berson NL (1946) Construction of pseudoareola. Surgery 20(6):808

14. Adams WM (1949a) Labial transplant for correction of loss of nipple. Plast Reconstr Surg 4:295

15. Brent B, Bostwick J (1977) Nipple-areola reconstruction with auricular tissues. Plast Reconstr Surg. 60(3):353-61

16. Muruci A, Dantas JJ, Noguerira LR (1978) Reconstruction of the nipple-areola complex. Plast Reconstr Surg 61(4):558-560. https://doi.org/10.1097/00006534-197804000-00010

17. Adams WM (1949b) Labial transplant for correction of loss of the nipple. Plast Reconstr Surg 4(3):295-298. https://doi.org/10. 1097/00006534-194905000-00009

18. Hartrampf CR, Culbertson JH (1984) A dermal-fat flap for nipple reconstruction. Plast Reconstr Surg 73(6):982-986. https://doi.org/10.1097/00006534-198406000-00027

19. Broadbent TR, Woolf RM, Metz PS (1977) Restoring the mammary areola by a skin graft from the upper inner thigh. Br J Plast Surg 30(3):220-222 (PMID: 329932)

20. Nagura-Inomata N, Iwahira Y, Hayashi N, Komiya T, Takahashi O (2016) The optimal reconstruction size of nipple-areola complex following breast implant in breast cancer patients. Springerplus 5(1):579. https://doi.org/10.1186/s40064-0162230-5

21. Seaman BJ, Akbari SR, Davison SP (2012) A novel technique for nipple-areola complex reconstruction: the acellular dermal matrix onlay graft. Plast Reconstr Surg 129(3):580e-e581. https://doi.org/10.1097/PRS.0b013e3182419c68

22. Millard DR Jr, Devine J Jr, Warren WD (1971) Breast reconstruction: a plea for saving the uninvolved nipple. Am J Surg 122(6):763-764. https://doi.org/10.1016/0002-9610(71)90441-7 
23. Little JW (2003) Cryopreserved autologous nipple-areola complex transfer to the reconstructed breast-Discussion. Plast Reconstr Surg 111(1):148-149. https://doi.org/10.1097/01.PRS. 0000046801.58544 .04

24. Nakagawa T, Yano K, Hosokawa K (2003) Cryopreserved autologous nipple-areola complex transfer to the reconstructed breast. Plast Reconstr Surg 111(1):141-149. https://doi.org/10. 1097/01.PRS.0000037863.12680.39

25. Bunchman HH 2nd, Larson DL, Huang TT, Lewis SR (1974) Nipple and areola reconstruction in the burned breast. the "double bubble" technique. Plast Reconstr Surg 54(5):531-536. https://doi.org/10.1097/00006534-197411000-00002

26. Becker H (1986) The use of intradermal tattoo to enhance the final result of nipple-areola reconstruction. Plast Reconstr Surg 77(4):673-676. https://doi.org/10.1097/00006534-19860400000032

27. Millard DR Jr (1972) Nipple and areola reconstruction by splitskin graft from the normal side. Plast Reconstr Surg 50(4):350-353. https://doi.org/10.1097/00006534-19721000000006

28. Spear SL, Schaffner AD, Jespersen MR, Goldstein JA (2011) Donor-site morbidity and patient satisfaction using a composite nipple graft for unilateral nipple reconstruction in the radiated and nonradiated breast. Plast Reconstr Surg 127(4):1437-1446. https://doi.org/10.1097/PRS.0b013e318208d107

29. Bodin F, Bruant-Rodier C, Ruffenach L, Dissaux C (2018) La reconstruction de l'aréole et du mamelon [The reconstruction of the nipple-areolar]. Ann Chir Plast Esthet 63(5-6):559-568. https://doi.org/10.1016/j.anplas.2018.06.010

30. Haslik W, Nedomansky J, Hacker S, Nickl S, Schroegendorfer KF (2015) Objective and subjective evaluation of donor-site morbidity after nipple sharing for nipple areola reconstruction. J Plast Reconstr Aesthet Surg 68(2):168-174. https://doi.org/10. 1016/j.bjps.2014.10.023

31. Friebel T, Gardiner S, Naji S, Mathur B (2020) Nipple sharing: an undervalued technique in nipple reconstruction. Abs.amegroups.com. Available from: https://abs.amegroups. com/article/view/4557

32. Krogsgaard SHH, Carstensen LF, Thomsen JB, Rose M (2019) Nipple reconstruction: a novel triple flap design. Plast Reconstr Surg Glob Open 7(5):e2262. https://doi.org/10.1097/GOX. 0000000000002262

33. Rem K, Al Hindi A, Sorin T, Ozil C, Revol M, Mazouz DS (2016) Nipple reconstruction after implant-based breast reconstruction in radiated patients: a new safe dermal flap. J Plast Reconstr Aesthet Surg 69(5):617-622. https://doi.org/10.1016/j. bjps.2015.12.022

34. Chia HL, Wong M, Tan BK (2014) Nipple reconstruction with rolled dermal graft support. Arch Plast Surg 41(2):158-162. https://doi.org/10.5999/aps.2014.41.2.158

35. Kim JH, Ahn HC (2016) A revision restoring projection after nipple reconstruction by burying four triangular dermal flaps. Arch Plast Surg 43(4):339-343. https://doi.org/10.5999/aps. 2016.43.4.339

36. Bernard RW, Beran SJ (2003) Autologous fat graft in nipple reconstruction. Plast Reconstr Surg 112(4):964-968. https://doi. org/10.1097/01.PRS.0000076245.12249.BE

37. Mori H, Uemura N, Okazaki M (2015) Nipple reconstruction with banked costal cartilage after vertical-type skin-sparing mastectomy and deep inferior epigastric artery perforator flap. Breast Cancer 22(1):95-97. https://doi.org/10.1007/s12282-0110329-7

38. Guerid S, Boucher F, Mojallal A (2017) Nipple reconstruction using rib cartilage strut in microsurgical reconstructed breast. Ann Chir Plast Esthet 62(4):332-335. https://doi.org/10.1016/j. anplas.2017.02.002
39. Jankau J, Jaśkiewicz J, Ankiewicz A (2011) A new method for using a silicone rod for permanent nipple projection after breast reconstruction procedures. Breast 20(2):124-128. https://doi. org/10.1016/j.breast.2010.10.001

40. Evans KK, Rasko Y, Lenert J, Olding M (2005) The use of calcium hydroxylapatite for nipple projection after failed nippleareolar reconstruction: early results. Ann Plast Surg 55(1):25-29. https://doi.org/10.1097/01.sap.0000168370.81333. 97

41. Oliver JD, Beal C, Hu MS, Sinno S, Hammoudeh ZS (2020) Allogeneic and alloplastic augmentation grafts in nipple-areola complex reconstruction: a systematic review and pooled outcomes analysis of complications and aesthetic outcomes. Aesthetic Plast Surg 44(2):308-314. https://doi.org/10.1007/s00266019-01539-7

42. Yanaga H (2003) Nipple-areola reconstruction with a dermal-fat flap: technical improvement from rolled auricular cartilage to artificial bone. Plast Reconstr Surg 112(7):1863-1869. https:// doi.org/10.1097/01.PRS.0000091243.42112.32

43. Wong RK, Wichterman L, Parson SD (2008) Skin sparing nipple reconstruction with polytetrafluoroethylene implant. Ann Plast Surg 61(3):256-258. https://doi.org/10.1097/SAP. 0b013e31815d5bfa

44. Bertozzi N, Simonacci F, Pesce M, Santi P, Raposio E (2018) Nipple reconstruction techniques: which is the best choice? Open Med J 5(1):62-75. https://doi.org/10.2174/ 1874220301805010062

45. Khoo D, Ung O, Blomberger D, Hutmacher DW (2019) Nipple reconstruction: a regenerative medicine approach using $3 \mathrm{~d}-$ printed tissue scaffolds. Tissue Eng Part B Rev 25(2):126-134. https://doi.org/10.1089/ten.TEB.2018.0253

46. Pashos NC, Scarritt ME, Eagle ZR, Gimble JM, Chaffin AE, Bunnell BA (2017) Characterization of an acellular scaffold for a tissue engineering approach to the nipple-areolar complex reconstruction. Cells Tissues Organs 203(3):183-193. https:// doi.org/10.1159/000455070

47. Halvorson EG, Cormican M, West ME, Myers V (2014) Threedimensional nipple-areola tattooing: a new technique with superior results. Plast Reconstr Surg 133(5):1073-1075. https:// doi.org/10.1097/PRS.0000000000000144

48. Ricci JA, Halvorson EG (2018) Three-Dimensional NippleAreola Tattooing. In: Shiffman M (ed) Nipple Areolar Complex Reconstruction. Springer, Cham, pp 373-377

49. Jenkins M, Patel S (2016) Assessment of risk factors associated with nipple reconstruction. Breast J 22(4):377-378. https://doi. org/10.1111/tbj.12598

50. Satteson ES, Reynolds MF, Bond AM, Pestana IA (2016) An analysis of complication risk factors in 641 nipple reconstructions. Breast J 22(4):379-383. https://doi.org/10.1111/tbj.12591

51. Zoghbi Y, Borsting EA, Chim JH, Panthaki ZJ (2018) Smoking as a risk factor for wound dehiscence in nipple reconstruction: an analysis of 1683 cases. Breast J 24(1):99-100. https://doi.org/ 10.1111/tbj. 12844

52. Bonomi S, Settembrini F, Gregorelli C, Rapisarda V (2011) Patient selection and satisfaction following nipple reconstruction with nipple sharing. J Plast Reconstr Aesthet Surg 64(12):e339e340. https://doi.org/10.1016/j.bjps.2011.08.031

53. Zenn MR, Garofalo JA (2009) Unilateral nipple reconstruction with nipple sharing time for a second look. Plast Reconstr Surg 123(6):1648-53. https://doi.org/10.1097/PRS. 0b013e3181a3f2f9

54. Hong KY, Kim YE, Minn KW, Jin US (2017) Immediate nipple reconstruction during implant-based breast reconstruction. Aesthet Plast Surg 41(4):793-799. https://doi.org/10.1007/ s00266-017-0804-4 
55. Chao AH (2017) The delay phenomenon in the setting of prior irradiation: a matched-pair analysis in nipple reconstruction. Plast Reconstr Surg 140(2):365e-366e. https://doi.org/10.1097/ PRS.0000000000003557

56. Riccio CA, Zeiderman MR, Chowdhry S, Wilhelmi BJ (2015) Review of nipple reconstruction techniques and introduction of $\mathrm{v}$ to $\mathrm{y}$ technique in a bilateral wise pattern mastectomy or reduction mammaplasty. Eplasty 15:e11 (PMID: 25987936)

57. Lewin R, Amoroso M, Plate N, Trogen C, Selvaggi G (2016) The aesthetically ideal position of the nipple-areola complex on the breast. Aesthetic Plast Surg 40(5):724-732. https://doi.org/ 10.1007/s00266-016-0684-Z

58. Laschuk MJ, Head LK, Roumeliotis GA, Xuan L, Silverman HJ (2019) The rule of thirds: determining the ideal areolar proportions. JPRAS Open 23:55-59. https://doi.org/10.1016/j.jpra. 2019.11.001

59. Patel KM, Nahabedian MY (2012) Reconstruction of the nippleareola complex. In: Neligan P, Gurtner G, Rubin J, Rodriguez E, Losee J, Song D, Nahabedian M (eds) Chang J Plast Surg. Elservier Ltd., New York, pp 498-520

60. Sanuki J, Fukuma E, Uchida Y (2009) Morphologic study of nipple-areola complex in 600 breasts. Aesthetic Plast Surg. 33(3):295-297. https://doi.org/10.1007/s00266-008-9194-y

61. Hauben DJ, Adler N, Silfen R, Regev D (2003) Breast-areolanipple proportion. Ann Plast Surg 50(5):510-513. https://doi. org/10.1097/01.SAP.0000044145.34573.F0

62. Garramone CE, Lam B (2007) Use of AlloDerm in primary nipple reconstruction to improve long-term nipple projection. Plast Reconstr Surg 119(6):1663-1668. https://doi.org/10.1097/ 01.prs.0000258831.38615.80

63. Pestana IA, Coan B, Erdmann D, Marcus J, Levin LS, Zenn MR (2009) Early experience with fluorescent angiography in freetissue transfer reconstruction. Plast Reconstr Surg 123(4):1239-1244. https://doi.org/10.1097/PRS. $0 \mathrm{~b} 013 \mathrm{e} 31819 \mathrm{e} 67 \mathrm{c} 1$

64. Shestak KC, Gabriel A, Landecker A, Peters S, Shestak A, Kim J (2002) Assessment of long-term nipple projection: a comparison of three techniques. Plast Reconstr Surg 110(3):780-786. https://doi.org/10.1097/00006534-200209010-00010

65. Jung Y, Lee J, Lee S, Bae Y (2017) Immediate nipple reconstruction with a C-V flap and areolar reconstruction with an autograft of the ipsilateral areola. ANZ J Surg 87(12):E300E304. https://doi.org/10.1111/ans.13626

66. Filobbos G, Hamnett N, Hardwicke J, Skillman J (2017) Immediate nipple reconstruction in combination with implant reconstruction using dermal sling. Breast J 23(6):723-725. https://doi.org/10.1111/tbj.12904

67. Gougoutas A, Said H, Um G, Chapin A, Mathes D (2018) Nipple-areola complex reconstruction. Plast Reconstr Surg 141:404e-416e. 0000000000004166

68. Liliav B, Loeb J, Hassid VJ, Antony AK (2014) Single-stage nipple-areolar complex reconstruction technique, outcomes, and patient satisfaction. Ann Plast Surg 73(5):492-497. https://doi. org/10.1097/SAP.0b013e318276dac0

69. Sagrillo D (2004) Patient education: instructions following nipple reconstruction. Plast Surg Nurs 24(4):176. https://doi.org/ 10.1097/00006527-200410000-00010

70. Monteiro DT (1995) Secure dressing after nipple-areola reconstruction. Ann Plast Surg 35(2):220-221. https://doi.org/10. 1097/00000637-199508000-00019

71. Papay FA, Lucas A, Hutton D (1997) A simple postoperative stent dressing after nipple-areola reconstruction. Plast Reconstr Surg 99(6):1787-1788. https://doi.org/10.1097/00006534199705010-00060
72. Liew S, Disa J, Cordeiro PG (2001) Nipple-areolar reconstruction: a different approach to skin graft fixation and dressing. Ann Plast Surg 47(6):608-611. https://doi.org/10.1097/00000637200112000-00004

73. Saravolac V, Whitaker I, Grinsell D (2013) An algorithm for maintaining nipple projection following nipple reconstruction. Eur J Plast Surg 37(1):53-54

74. Lim J, Sahu A (2011) Improving the success of nipple reconstruction. Ann R Coll Surg Engl 93(8):648. https://doi.org/10. 1308/003588411x13165261994238c

75. Salgarello M, Cervelli D, Barone-Adesi L (2008) The use of a silicone nipple shield as protective device in nipple reconstruction. J Plast Reconstr Aesthet Surg 61(11):1396-1398. https://doi.org/10.1016/j.bjps.2008.02.033

76. Weissman O, Tessone A, Liran A et al (2010) Silicone nipple shields: an innovative postoperative dressing technique after nipple reconstruction. Aesthet Plast Surg 34(1):48-51. https:// doi.org/10.1007/s00266-009-9426-9

77. Sircar T, Chouhan A, Johri A (2010) Cartella eye-shield as a dressing after nipple reconstruction-a technical innovation. Ann R Coll Surg Engl 92(5):439-440. https://doi.org/10.1308/ 003588410x12699663903719d

78. Staruch RMT, Din AH, See MS, Mohanna PN (2019) The ideal nipple reconstruction shield. Plast Reconstr Surg 143(3):698-699. https://doi.org/10.1097/PRS. 0000000000005318

79. Rosing JH, Momeni A, Kamperman K, Kahn D, Gurtner G, Lee GK (2010) Effectiveness of the asteame nipple guard tm in maintaining projection following nipple reconstruction: a prospective randomised controlled trial. J Plast Reconstr Aesthet Surg 63(10):1592-1596. https://doi.org/10.1016/j.bjps.2009.10. 006

80. Kristoffersen CM, Seland H, Hansson E (2017) A systematic review of risks and benefits with nipple-areola-reconstruction. J Plast Surg Hand Surg 51(5):287-295. https://doi.org/10.1080/ 2000656X.2016.1251935

81. O'Donnell MAHJ (1994) What does the patient consider the important features of the reconstructed nipple and the donor nipple? Oral presentation at the Winter Meeting of the British Association of Plastic Surgeons (BAPS), London, UK, 1 Dec 1994

82. Craft RO, May JW Jr (2011) Staged nipple reconstruction with vascularized SurgiMend acellular dermal matrix. Plast Reconstr Surg 127(6):148e-e149. https://doi.org/10.1097/PRS. 0b013e3182131e74

83. Starnoni M, Baccarani A, Pinelli M, Pedone A, De Santis G (2020) Tattooing of the nipple-areola complex: what not to do a case series. Ann Med Surg (Lond) 55:305-307. https://doi.org/ 10.1016/j.amsu.2020.05.041

84. Momoh AO, Colakoglu S, de Blacam C et al (2012) The impact of nipple reconstruction on patient satisfaction in breast reconstruction. Ann Plast Surg 69(4):389-393. https://doi.org/10. 1097/SAP.0b013e318246e572

85. Jabor MA, Shayani P, Collins DR Jr, Karas T, Cohen BE (2002) Nipple-areola reconstruction: satisfaction and clinical determinants. Plast Reconstr Surg 110(2):457-465. https://doi.org/10. 1097/00006534-200208000-00013

86. Bykowski MR, Emelife PI, Emelife NN, Chen W, Panetta NJ, de la Cruz C (2017) Nipple-areola complex reconstruction improves psychosocial and sexual well-being in women treated for breast cancer. J Plast Reconstr Aesthet Surg 70(2):209-214. https://doi.org/10.1016/j.bjps.2016.10.009

87. Gilleard O, Bowles PF, Tay SK, Jones ME (2015) The influence of breast mound reconstruction type on nipple reconstruction projection. J Plast Reconstruct Aesthetic Surg JPRAS 68(9):1310-1311. https://doi.org/10.1016/j.bjps.2015.04.023 
88. Cheng MS, Ho CM, Cheung WY, Or A, Wong WM (2004) Nipple-areola reconstruction in autologous breast reconstruction: Chinese patients' perspective. Ann Plast Surg 53(4):328-333. https://doi.org/10.1097/01.sap.0000137247. 53249.a1

89. Allison AB, Howorth MG Jr (1978) Carcinoma in a nipple preserved by heterotopic auto-implantation. N Engl J Med 298(20):1132. https://doi.org/10.1056/NEJM197805182982007

90. Rose JH Jr (1980) Carcinoma in a transplanted nipple. Arch Surg 115(9):1131-1132. https://doi.org/10.1001/archsurg.1980. 01380090095023

91. Nava MB, Cortinovis U, Ottolenghi J et al (2006) Skin-reducing mastectomy. Plast Reconstr Surg 118(3):603-613. https://doi. org/10.1097/01.prs.0000233024.08392.14

92. Wei F, Mardini S (2016) Flaps and reconstructive surgery. 2nd ed. Philadelphia PA: Elsevier-Health sciences division. [Part 1Principles. Chapter 2-Classification of flaps. Expert commentary by saint-Cyr Michel (p. 9)] https://www.clinicalkey.com/ dura/browse/bookChapter/3-s2.0-B9780721605197X00019

93. Lee TJ, Noh HJ, Kim EK, Eom JS (2012) Reducing donor site morbidity when reconstructing the nipple using a composite nipple graft. Arch Plast Surg 39(4):384-389. https://doi.org/10. 5999/aps.2012.39.4.384

94. Lee JS, Eom JR, Lee JW et al (2019) Safe delayed procedure of nipple reconstruction in poorly circulated nipple. Breast $\mathbf{J}$ 25(1):129-133. https://doi.org/10.1111/tbj.13167
95. Din A, Farhadi J (2018) Reconstruction of the nipple-areolar complex: an algorithm for decision-making. Nipple-Areolar Complex Reconstruct. https://doi.org/10.1007/978-3-31960925-6_56

96. Kaplan J, Reece E, Belfort B, Winocour S (2020) Repeated C-V flap for loss of projection in nipple reconstruction. Plast Reconstr Surg 145(4):884e-885e. https://doi.org/10.1097/PRS. 0000000000006690

97. Rubino C, Dessy LA, Posadinu A (2003) A modified technique for nipple reconstruction: the "arrow flap." $\mathrm{Br}$ J Plast Surg 56(3):247-251. https://doi.org/10.1016/s0007-1226(03)00094-8

98. Alfano C, Tenna S, Caggiati A, Campanella A (2004) Nipple reconstruction by local flaps: a long-term comparative study between star and skate techniques. Acta Chir Plast 46(4):127-131

99. Kroll SS, Reece GP, Miller MJ et al (1997) Comparison of nipple projection with the modified double-opposing tab and star flaps. Plast Reconstr Surg 99(6):1602-1605

100. Pizzonia G, Sasso A, Rossello C (2017) Alternative technique for nipple-areola complex reconstruction with poor skin condition. ANZ J Surg 87(10):E121-E124. https://doi.org/10.1111/ ans. 13176

Publisher's Note Springer Nature remains neutral with regard to jurisdictional claims in published maps and institutional affiliations. 